\title{
O cinema como fonte histórica e como representação social: alguns apontamentos
}

\author{
Felipe Pereira da Silva Davson* \\ felipedavson@hotmail.com
}

\begin{abstract}
Resumo
O presente artigo tem como proposta analisar o cinema como fonte documental no trabalho do historiador. Para embasar este posicionamento, foi utilizada a obra de Marc Ferro (1976) O cinema: uma contra-análise da História? os trabalhos de Marcos Napolitano (2008) e Eduardo Morettin (2003). Para ampliar o debate, foram realizados apontamentos sobre o cinema como forma de representação social a partir de uma perspectiva sociocultural de suas práticas e representações, conceitos propostos por Roger Chartier (2002). Para fundamentar e exemplificar os pressupostos teóricos utilizados foi apresentada uma análise do filme O Judeu Suss (1940) de Veit Harlan. A metodologia se deu através da análise de conteúdo do filme, no qual se observou a linguagem cinematográfica produzida desta película. Os resultados destas análises mostraram que alguns estereótipos colocados nas cenas serviram para propagar um ódio contra o povo judeu. Esses resultados são reafirmados em uma abordagem pós-fílmica, que são os registros sobre a crítica e recepção por parte do público no período de lançamento do Judeu Suss.
\end{abstract}

\section{Palavras-chave}

Cinema e História; Representação Social; História Cultural

\section{Cinema as a Historical Source and as a Social Representation: Some Notes}

\begin{abstract}
This article aims to analyze cinema as a documentary source in the historian's work. To support this positioning, the work of Marc Ferro (1976) was used The cinema: a counteranalysis of History? As well as the writings of Marcos Napolitano (2008) and Eduardo Morettin (2003). To broaden the debate, notes will also be made on cinema as a form of social representation from a sociocultural perspective of its practices and representations, concepts proposed by Roger Chartier (2002). In order to base and exemplify the theoretical assumptions used, an analysis of the film O Judeu Suss (1940) of Veit Harlan will be presented. The methodology was based on the content analysis of the film, where the cinematic language produced in this film was observed. The results of these analyzes showed that some stereotypes placed in the scenes served to propagate a hatred against the Jewish people. These results are reaffirmed in a post-film approach, which are the records on criticism and reception by the public in the Jewish Suss launch period.
\end{abstract}

\section{Keywords}

Cinema and History; Social Representation; Cultural History 


\section{Introdução}

O texto pretende analisar a possibilidade de fazer com que alguns objetos insatisfatórios e negligenciados, em específico o cinema, começassem a ser vistos como fonte histórica a partir da terceira geração da Escola dos Annales através de Marc Ferro (1971). Dentro desse contexto, o historiador pode trabalhar o seu objeto de estudo, começando o diálogo com a fonte escolhida. Lembrando: não existe neutralidade, nem documento isento de conotações políticas ou ideológicas como bem argumentou Jacques Le Goff (2010):

O documento não é inócuo. É, antes de mais nada, o resultado de uma montagem, consciente ou inconsciente, da história, da época, da sociedade que o produziram, mas também das épocas sucessivas durante as quais continuou a viver, talvez esquecido, durante as quais continuou a ser manipulado, ainda que pelo silêncio. $O$ documento é uma coisa que fica, que dura, o testemunho, o ensinamento (para evocar a etimologia) que ele traz devem ser em primeiro lugar analisados, desmistificando the o seu significado aparente (GOFF, 2010, p. 538).

A Escola dos Annales foi responsável por modificações no que tange às fontes com que trabalha o historiador. Com novas abordagens, perspectivas e métodos o historiador pôde ampliar o seu campo de investigação. Com essas transformações ocorridas no século $\mathrm{XX}$, a História Cultural também ganhou destaque. Chartier (2002) a define bem: “A história cultural tal como a entendemos tem por principal objeto identificar o modo como diferentes lugares e momentos uma determinada realidade social é construída, pensada, dada a ler." (p. 16).

Assim, o presente artigo irá analisar o filme sob a perspectiva de uma fonte histórica, verificada por alguns historiadores, alguns pioneiros nesse trabalho, como Marc Ferro (1976), e posteriormente críticos dele como Marcos Napolitano (2008) e Eduardo Morettin (2003) na busca de ampliar os seus trabalhos. Além da utilização do cinema como uma representação social, conceito esse difundido pelo historiador Roger Chartier (2007) que o descreve de várias maneiras, como "uma noção que permite vincular estreitamente as posições e as relações sociais com a maneira como os indivíduos e os grupos se percebem e percebem os demais" (2007, p. 49).

A abordagem se dará pela análise documental, na qual será realizada uma investigação do seu conteúdo, da construção fílmica e de sua linguagem cinematográfica, tendo como exemplo a propaganda e o impacto que o filme $O$ Judeu Suss ocasionou em sua divulgação pela Alemanha. Busca-se evidenciar a utilização do cinema como mais uma fonte histórica, que, a cada pesquisa, aprofunda seus métodos e investigações, para ampliar o debate e as teorias oriundas da História Social e Cultural, sobretudo, do cinema.

\section{O cinema}

O cinema é um objeto de reprodução de imagens, ou de "fotografias em movimento", como dizia o crítico de cinema francês, André Bazin. O mesmo surgiu no final do século XIX como uma das invenções da tida modernidade e logo alcançou regiões inimagináveis. Derivou de outros aparelhos óticos que foram aperfeiçoados, como o Praxinoscópio ou o Zootropo, instrumentos esses confeccionados pelas invenções modernas (ROSENFELD, 2002).

O cinema, bem como outros aparatos tecnológicos, entraram cada vez mais em contato com o público e despertaram um interesse crescente pela representação do real (PESAVENTO, 1995). Mas, em contraponto dessas possibilidades, para Anatol Rosenfeld, a produção de filmes tinha como fator mais importante $o$ interesse por lucros, interesse esse visto até os dias atuais. Para ele, o cinema é um filho do capitalismo, logo: 
O cinema, por sua vez, não teria eventualmente ultrapassado o estágio de mera curiosidade e de instrumento cientifico para reproduzir o movimento se a sua invenção não tivesse coincidido com o desenvolvimento de um grande proletariado demasiadamente pobre para frequentar o teatro e os espetáculos não mecanizados (ROSENFELD, 2002, p. $63)$.

Para Rosenfeld (2002), esse invento ganhou notoriedade e, alguns anos depois torna-se uma arte, oriunda de avanços tecnológicos. Mesmo sendo uma indústria de entretenimento, o cinema assume dimensões e uma linguagem própria, além de correntes cinematográficas como o Neorrealismo Italiano, o Expressionismo Alemão, o Cinema Novo, dentre outros, fazendo surgir cursos e pesquisas.

Um autor pioneiro frequentemente citado é o teórico Walter Benjamin (2000), pelo seu trabalho $A$ obra de arte na era de sua reprodutibilidade técnica, originalmente escrita em 1934, mas só publicado postumamente, em 1952. Nessa obra ele elabora um importante panorama sobre as técnicas de reprodução da arte, desde os gregos com a fundição, a xilogravura durante a Idade Média, e no século XIX, a litografia, fazendo, assim, a proliferação e uma reprodução em escala maior. De acordo com ele, foi com a fotografia que a obra ficou mais rápida de se copiar, do que a própria palavra.

Nesse processo, Benjamin observa a perda da aura, que seria um tipo de recepção, devido à reprodução de um objeto que antes, além de peça única, tinha um valor de culto. Assim que ganha uma conotação coletiva, acaba tendo um valor de exposição superior, tirando assim a autenticidade da obra. Para ele, “o que faz com que uma coisa seja autêntica é tudo aquilo que ela contém de originalmente transmissível, desde sua duração material até seu poder de testemunho histórico" (2000, p. 225).
Esse autor explica que, quando uma obra perde sua função ritual, perde assim sua aura. É nesse contexto que ele observa o surgimento do cinema, como um aparato técnico de reprodução, que vai ter um público cada vez mais crescente, ganhando assim, as massas. Além de aprofundar a percepção do espectador.

Benjamin (2000) também verifica diferenças entre o teatro e o cinema, como a função do ator. Pelo teatro, o ator ao interpretar um papel, o observador percebe a aura dessa personagem. Já no filme, o ator de cinema restringe o papel da aura, e se transforma em uma personalidade, que seria o star-sistem, tendo um valor mercantil capitalista de produção.

Além de outros aperfeiçoamentos no cinema como a iluminação, a montagem, o close-up, que, para o autor, "por conta de um grande plano, é o espaço que se amplia; por conta da câmera lenta, é o movimento que toma novas dimensões" (BENJAMIN, 2000, p. 246). Cita-se como exemplo uma pintura, que ao ser contemplada, poderá refletir sobre o que vê. Já o quadro do cinema, ao ser visto, tem passagem muito rápida, seguida de outras imagens, não dando tempo para o espectador se fixar a uma única. Logo, para Benjamin (2000), o expectador do cinema é um examinador, mas um que se distrai, devido aos choques de modificação dos cenários e dos lugares.

Heitor Capuzzo (1986), por sua vez, influenciado pelos escritos de Walter Benjamin, em seu livro Cinema: A aventura do sonho, de 1986, percebe o cinema como um filho da modernidade, assim como o telefone, o avião, a eletricidade. Para ele, o "cinema foi porta-voz de um período onde a burguesia apresentou seu poder de ação. Sua dinâmica ocorreu juntamente com o advento de outras invenções" (CAPUZZO, 1986, p. 13).

O cinema ia ganhando espaço, inicialmente, de um público simples, em sua maioria trabalhadores, para 
um mais elitizado, devido às modificações ocorridas pouco antes da primeira guerra mundial. Sklar (1975) destacou que as salas de cinema ficaram mais sofisticadas e, consequentemente, o ingresso mais caro. Com uma linguagem cinematográfica cada vez mais complexa, pode contar uma história por meio de uma narrativa, com uma dinâmica que vai de planos, sequências, closes e a sua montagem como um todo. Com som e cor, anos depois, ampliam seu leque de ações. Cria-se assim uma linguagem própria, deixa de ser considerado uma cópia do teatro, ou de outras expressões artísticas. Por fim, Capuzzo (1986) salienta:

O público elegeu no decorrer deste século, o cinema como porta-voz de um mundo além dos limites do real, idealizando na sua missão de eternizar uma poética visual que apreendeu da vida a dinâmica da ciência e do saber, aliada aos corações dos poetas (CAPUZZO, 1986, p. $38)$.

Assim, o cinema começou a ser visto como uma ferramenta da cultura de massa. Para Barros, (2012) como um instrumento de dominação, sendo, por exemplo, muito utilizado pelos nazistas na Alemanha, como forma de legitimação do seu poder e, também, pelos soviéticos, para enaltecer o regime socialista implantado na URSS.

Logo, o interesse para se estudar os filmes, o que estava inserido em seus discursos, na sua narrativa, em suas imagens, passa a ter destaque, não só entre os críticos de cinema, mas também nos meios acadêmicos. O que engendrou o fato de que não só o filme é analisado, mas toda sua rede, desde as filmagens, produção, distribuição, exibição e a recepção pelo espectador em um contexto sócio-histórico. Como salienta Schvarzman (2007), "O foco sai da tela para a sala, para o espectador, as significações simbólicas do cinema, a frequentação e as práticas sociais. Isso agregou rigor aos estudos de cinema, ampliou o foco, e tornou mais ricas as abordagens" (p. 36).

\section{O cinema como fonte histórica: apontamentos}

Em meados dos anos 1970, o historiador da terceira geração dos Annales, Marc Ferro (1971) foi um dos expoentes a utilizar filmes como objeto de estudo. Pois, para ele, os antigos historiadores só utilizavam os documentos tidos como oficiais. Nesse contexto, o filme era apenas um objeto manipulável, com partes selecionáveis, o que representava uma falsificação. Os pesquisadores não davam créditos ao cinema, pois eles trabalhavam numa caixa de vidro, segundo verificou Ferro.

Mas esse pensamento foi aos poucos perdendo espaços com os teóricos da "Nova História". O cinema aumentou seu estatuto de simples diversão, arte ou entretenimento e desenhou-se como fonte histórica, ou seja, "o filme é abordado não como uma obra de arte, porém como um produto, uma imagem-objeto, cujas significâncias não são somente cinematográficas" (FERRO, 1988, p, 203).

Assim não só o filme é analisado, mas todo o contexto da sua produção, distribuição, exibição, trilha sonora, dentre outros aspectos, tal como define o autor:

\begin{abstract}
É necessário aplicar esses métodos a cada substância dos filmes [...] às relações entre os componentes dessas substâncias; analisar o filme principalmente a narrativa, o cenário, o texto, as relações do filme com o que não é o filme: o autor, a produção, o público, a crítica, o regime. Pode-se assim esperar compreender não somente a obra como também a realidade que representa (FERRO, 1988, p, 203).
\end{abstract}

Outro ponto importante na análise de Ferro são as dicotomias: visível-não visível; aparente-latente; his- 
tória e contra-história; em que os produtores e diretores, ao filmarem uma cena, poderiam captar no registro fílmico, "aspectos do real". Quadros com imagens involuntárias, que seriam observadas pelo historiador. E a partir de uma análise minuciosa, seria visualizado algum regime totalitário ou mesmo algum tipo de resistência contra esse tipo de dominação. $\mathrm{O}$ autor verifica alguns filmes russos no período da Revolução Russa, no seu texto O filme uma contra-análise da história? (1971) Além de definir que qualquer filme sempre irá exceder seu conteúdo.

A pesquisa de Marc Ferro tem um aspecto seminal, já que o autor não se deteve a aprofundar tais estudos. Alguns teóricos posteriormente irão analisar seus estudos e encontrar algumas lacunas, como o historiador Eduardo Morettin (2003), em um texto intitulado O cinema como fonte histórica na obra de Marco Ferro. Nesse trabalho, o autor irá perceber que as dicotomias que citamos acima são por vezes simplistas, como a possibilidade de recuperar o não-visível do visível através de uma película. Seria contraditório, visto que, com isso tiraria o caráter polissêmico das imagens.

Para Morettin, a forma dessas conjunturas realçadas por Ferro só seriam possíveis se o pesquisador separasse aspectos da obra, como o enredo. Por exemplo, elementos paralelos como imagem e som. Mas o autor deixa claro sua visão: "pelo contrário, afirmamos que um filme pode abrigar leituras opostas acerca de um determinado fato, fazendo dessa tensão um dado intrínseco à sua própria estrutura interna" (MORETTIN, 2003, p. 15).

Outro ponto discutido por esse autor seria que, para Ferro, os mesmos métodos utilizados para filmes poderiam servir para a fotografia e para a televisão. Tirando assim suas especificidades como dispositivos distintos. Além de informar que historiadores do século XIX já tinham em mente a possibilidade de utilizar ou- tros objetos para além dos ditos oficiais, como a literatura, pinturas, peças ou algo que pudesse servir na falta de uma documentação mais tradicional. Para Morettin:

A preocupação central desses historiadores com relação à utilização das fontes tem ligação com a elaboração de uma metódica rigorosa que estabelece diversos critérios com o intuito de se chegar a um veredito sobre elas, dentro de um processo de construção cujo ponto final é o fato histórico (MORETTIN, 2003, p. 22).

Percebemos a importância que se dá com o manuseio das fontes, mesmo com as limitações ocorridas no século XIX, as suas diversificações e abordagens teóricas e práticas. Porém, com esses apontamentos críticos na obra de Ferro, como visualizamos acima, não se poderia tirar a excepcionalidade do trabalho desse pesquisador, e a importância das transformações ocorridas com o trabalho do historiador para com a relação Cinema e História.

Logo, a partir dos anos setenta, o cinema passa a ser visto como um documento e novos trabalhos são produzidos e direcionados por essa perspectiva (CARDOSO, 2013). A relação entre Cinema e História vai além desses pressupostos, já que novos campos de pesquisa vão sendo construídos. Pode-se definir essa relação em três categorias: o cinema na história, a história no cinema e a história do cinema, ambas interligadas, mas com suas especificidades. Assim nos define Marcos Napolitano:

O cinema na história é o cinema visto como fonte primária para a investigação historiográfica; a história no cinema é o cinema abordado como produto de discurso histórico e como interprete do passado e finalmente, a história do cinema enfatiza o estudo dos avanços técnicos, da linguagem cinematográfica e condições sociais de reprodução e recepção dos filmes (NAPOLITANO, 2010, p. 240). 
No primeiro ponto, o cinema na história é o que estamos trazendo neste tópico. O segundo ponto, a história no cinema, podemos investigar, a partir de algum filme, traços que nos ajudem a perceber, por meio de uma análise, o que a película queria passar ao utilizar uma história como narrativa, os chamados "filmes históricos". Podemos tomar como exemplo um filme produzido pelos nazistas, O Judeu Suss, de 1940, cujo aspecto central é mostrar para o público germânico como seria a figura do judeu, e como esse povo representava um aspecto negativo para a cultura alemã. Posteriormente, iremos verificar alguns pontos da sua linguagem cinematográfica.

O cinema pode servir como instrumento de pesquisa auxiliar de outras áreas, como uma ferramenta adicional para a história oral, ou mesmo registro étnico para alguma pesquisa de cunho antropológico (BARROS, 2012, p. 60). Além de ser verificado como "agente histórico", já que um filme pode influenciar um determinado setor da sociedade, em relação a roupas, acessórios ou produtos de variadas funções, bem como servir de manipulação ou sofrer algum tipo de censura. Ser um objeto a serviço da indústria cultural e com conotações claramente políticas e ideológicas (2012, p. $62)$.

Assim podem-se verificar os vários usos e formas de se utilizar o cinema como fonte para o estudo da história, como análise do passado por meio de imagens fílmicas que não tinham essa função ao serem registradas em cena, ou como diria Lagny (2012, p. 115) os filmes "nos deixam vestígios concretos do passado". Por fim, vale ressaltar, segundo José D’Assunção Barros, a importância da fonte cinematográfica para a História Cultural.

A fonte cinematográfica, particularmente a fonte filmica, torna-se evidentemente uma documentação imprescindivel para a história cultural- uma vez que ela revela imaginários, visões de mundo, padrões de comportamento, mentalidades, sistemas de hábitos, hierarquias sócias cristalizadas em formações discursivas e tantos outros aspectos vinculados aos de determinada sociedade historicamente localizada (BARROS, 2012, p. 68).

\section{Cinema como representação social: alguns aspectos}

O conceito de representação como já visualizado anteriormente, passou a ser difundido por Roger Chartier (2002), contribuindo assim para a História Cultural. As noções de práticas e representações seriam os "modos de fazer" e os "modos de ver". Barros (2005) menciona que "tanto os objetos culturais seriam produzidos 'entre práticas e representações', como os sujeitos produtores e receptores de cultura circulariam entre estes dois polos, que de certo modo corresponderiam respectivamente" (p.8).

Já as práticas culturais seriam "os modos como, em uma dada sociedade, os homens falam e se calam, comem e bebem, sentam-se e andam, conversam ou discutem, solidarizam-se ou hostilizam-se, morrem ou adoecem, tratam seus loucos ou recebem os estrangeiros" (BARROS, 2005, p. 8), visto que essas práticas se proliferam entre a sociedade por meio de representações bem definidas e construídas estrategicamente, como roupas, acessórios ou produtos que aparecem em cenas de filmes. Logo, pode-se utilizar esses conceitos em relação ao cinema, que, para Codato (2010):

\footnotetext{
É uma representação de imagens em movimento, imagens que colocam em relação o real e o imaginário através de um mecanismo que permite uma dupla articulação da consciência, no qual o espectador percebe a ilusão, mas também o dinamismo da realidade (CODATO, 2010, p.53)
}

Os filmes são dotados de sentido, desde a sua narrativa até o motivo que levou o diretor a realizar tal 
película. O próprio Ferro (1976), em seus trabalhos, analisou filmes soviéticos e alemães e percebeu como por meio de representações sociais, o nazismo ganhava fôlego, através de uma forte propaganda, a exemplo de filmes como o Judeu Juss, ou O Triunfo da Vontade, que, por meio de uma montagem direcionada, de uma trilha sonora triunfante, dentre outros aspectos que mostravam como as forças do Reich alemão ecoavam pelos cantos de um país pronto para a batalha.

Assim, filmes com teor político e ideológico, como os citados anteriormente, são práticas cinematográficas importantes para se analisar a questão do poder no período em que a película foi produzida e reproduzida, ou seja, sua relação entre as representações ao que se queria prefigurar e as práticas que pretendiam alcançar com o público em questão. Logo:

O cinema é compreendido como uma linguagem imagética constitutiva do tecido social e que apresenta o imaginário do cineasta e suas representações do cotidiano vivido com as tensões, conflitos e embates da realidade social, assim como a construção dos personagens e de suas múltiplas tramas são representações de mundo do cineasta que demonstram seus valores, comportamentos e sentimentos (AVELINO; FLÓRIO, 2013, p. 7).

O historiador passa a ter mais cuidado com a sua fonte, no caso o cinema, que passa a ser um "lugar das construções e projeções do imaginário, da aferição de sensibilidades e práticas sociais, lugar de representação" (SCHVARZMAN, 2007, p.18). Esses modos de ver seriam os modos pelos quais se conseguem visualizar as encenações, subjetividades, sentimentos, reações ou o "espelho onde se observa a forma de encenar a mulher, ou o homem: as representações" (IDEM, 2007, p. 36).
Já os modos de fazer, as práticas cinematográficas, a exemplo o filme $O$ Triunfo da Vontade, como analisa Lagny (2009, p. 121) "a multiplicação das câmeras permitirá fazer destacar o carisma do líder e a ordem disciplinada da multidão reforça os efeitos afetivos". Ou seja, a direção fílmica vem voluntariamente redobrar uma encenação deliberada, destinada a impressionar as multidões, para acentuar e incrementar a manipulação. Por fim, Lagny (2009) destaca que:

$$
\begin{aligned}
& \text { Está claro, portanto que o cinema é fonte } \\
& \text { de história, não somente ao construir } \\
& \text { representações da realidade, especificas } \\
& \text { e datadas, mais fazendo emergir manei- } \\
& \text { ras de ver, de pensar, de fazer e de sen- } \\
& \text { tir. Ele é fonte para a história, ainda que } \\
& \text { como documento histórico, o filme não } \\
& \text { produza, nem proponha nunca um } \\
& \text { "reflexo" direto da sociedade (LAGNY, } \\
& 2009, \text { p. 110). }
\end{aligned}
$$

Assim, nota-se que o filme precisa de uma investigação rigorosa e com métodos apurados para verificar que tipos de representações estão sendo construídas. Qual o intuito de se propagarem esses modos de ver, para que um determinado grupo faça disso uma prática social.

A fim de que se fabriquem artifícios para a construção de uma subjetividade centrada em aspectos pré-estabelecidos, como no caso da representação do judeu, de modo a criar uma ojeriza por boa parte dos alemães que foram ver o filme o Judeu Suss nos cinemas, na década de 1940, no território alemão e em outros países anexados posteriormente pelo avanço hitlerista (GONZALES, 2014). E as múltiplas interpretações que foram dadas ao povo semita, sendo fruto de uma construção nazista bem estudada e, ao mesmo tempo, bem deformada, na qual será constatada a seguir. 


\section{Judeu Suss: uma breve análise fílmica}

O filme alemão Judeu Suss foi produzido pela companhia Terra Films com direção inicial de Peter Brauen. Esse foi substituído por Veit Harlan e teve no roteiro Ludwig Metzger. O filme foi supervisionado pelo ministro da propaganda nazista, Joseph Goebbles.

Uma curiosidade é que o personagem do filme O judeu Suss existiu e se chamava Joseph Isaac Suss Oppenheimer. Esse personagem viveu no século XVIII, onde foi membro da corte de um duque da província de Württemberg. Ele, no entanto, acabou sendo executado por ter sido acusado de cometer práticas ilegais para a época.

Todavia, o filme em destaque não foi o único com essa temática, vale salientar que foi produzido um trabalho em 1934, na Inglaterra, com conotações positivas à história do judeu, baseado em um romance escrito em 1925, por Lion Feuchtwanger. Mas, segundo Gerda Gonzales (2014), o filme alemão não se utilizou dessa película como referência, já que sua intenção era exatamente outra.

Uma pesquisa foi feita em arquivos da época para ressaltar certa verossimilhança do personagem com o registro do próprio Joseph. Porém, para Gonzales (2014):

$O$ resultado do filme está longe de ser fidedigno aos fatos, visto que, além de possuir toda a interpretação antissemita, algumas das informações absorvidas nos documentos de acusação para o roteiro foram elaboradas pelo conselho de Württemberg, que havia condenado e que, portanto, era hostil a este ministro de finanças judeu do século XVIII (GONZALES, 2014, p. 48).
Segundo Gerda (2014, p. 51), atores judeus não eram bem vindos, mas o diretor, mesmo assim, solicitou alguns para fazerem papéis de judeus, para que pudesse, da melhor maneira possível, estereotipá-los. Foram trazidos 120 de guetos da Polônia, mas sumiram no percurso, sendo posteriormente deslocados outros figurantes vindos de Praga. Para a autora, "O filme promoveu um resultado que mistura a força ideológica nazista com a propaganda em formato de entretenimento, que Goebbels tanto almejava" (GERDA, 2014, p. 51).

Alguns dados são importantes para sua análise. O filme estreia em Veneza, em 5 de setembro de 1940, com um público estimado em mais de 20,3 milhões durante 3 (três) anos de exibição. Nessa época, a Alemanha já tinha conquistado um imenso território, passando assim, em todos os lugares dominados como a França, Itália, Romênia, Espanha dentre outros. Ficou, segundo estimativas da época, num total de 30 filmes lançados, na sexta colocação dos mais vistos. Além de ser exibido em campos de concentração, todos os soldados teriam que vê-lo (GONZALES, 2014). Após o sucesso alcançado e com o fim da guerra, além do esfacelamento do nazismo, o diretor Veit Harlan foi o único a ser julgado pela sua produção, mas foi absolvido em 1950.

Serão analisadas algumas cenas desse filme ${ }^{1}$, sob as representações sociais disseminadas por ele e suas consequentes práticas e apropriações para poder legitimar o seu discurso, bem como verificar a sua função como uma fonte histórica sobre a difusão nazista de propaganda para fazer da imagem do judeu um ser desprezível.

O filme começa revelando que se trata de uma biografia, já que informa que é baseado em fatos reais. 
A história se passa na cidade de Stuttgart, em 1733, onde acontece a nomeação de um duque, chamado Karl Alexandrer. A comunidade fica em festa, já se observa a intenção de mostrar o alemão como um ser de fé, que cumpre seu dever e suas leis. Além de uma personagem chamada Dorotheia, que é pura e amável, como toda mulher deveria ser, e irá casar-se com um bom homem.

Nesse momento sucessivo de quadros, dando a sequência a cena, aparecem os judeus. Percebe-se nitidamente a representação de um ser estereotipado que só pensa em dinheiro, lucro, fazendo qualquer coisa para ganhar, ou seja, infere-se, como no decorrer da película, sua representação será divulgada. Para Chartier (2009, p.49) "uma noção que permite vincular estreitamente as posições e as relações sociais com a maneira com os indivíduos, os grupos se percebem e percebem os demais". Nesse caso, como os alemães se veem e como enxergam os judeus.

Outro ponto do filme é quando Suss decide ir para a cidade. Para isso, devido à proibição da entrada dos judeus nela, precisa mudar sua aparência, que, para o povo semita, seria ir contra sua própria ideologia. Mas, nas cenas que se seguem, a personagem muda sua aparência, porque o que importa será seu lucro. Ou seja, a linguagem cinematográfica da película demonstra o caráter negativo, mas não só dele e sim de todos os que são judeus, afinal, a película pretende denegrir a imagem de toda a comunidade judaica. Fazendo essa representação não só como objeto, mas como uma operação (CHARTIER, 2009, p. 22).

Com a chegada dos judeus à cidade, os impostos aumentam, a comunidade sofre e decide protestar, mas é duramente reprimida, já que o duque está na mão de Suss, que coloca seu plano em ação: dominar através do duque, e obter o poder máximo. Até que os moradores conseguem reverter a situação e eliminam-no, pondo fim ao seu poder, e a "paz" volta, assim, à província de Württemberg. Para Marcos Napolitano (2008) “essas imagens do passado propiciam muito mais formas de memória- oficial ou debochada- do que a reflexão histórico-crítica daquele momento", no caso, ataque à comunidade judaica pelo nazismo.

Pode-se observar que esse filme não se propõe a esconder o seu real significado, ou uma contrahistória, seria necessária, como diria Ferro (1971). Mas como projeto de propaganda para enaltecer a "raça ariana" e representar o judeu como culpado por problemas enfrentados pela nação germânica e pela sua influência negativa e corrosiva. Assim, através da representação histórica de um contador de finanças, consegue-se salientar que "a segregação e o extermínio dos judeus que acontece no final do filme produzem cinematograficamente a "solução" encontrada pelos nazistas para a chamada "questão judaica" - o holocausto" (GONZALES, 2014, p. 55).

Com essa breve análise de algumas cenas do Judeu Suss, observou-se como um filme histórico, segundo Napolitano (2005, p. 246) parafraseando Pierre Sorlin, “ancora-se no presente e no passado". Ou seja, o historiador procura vestígios além do produto filme, como sua divulgação, distribuição, exibição, aspectos extrafílmicos, como a busca em arquivos, para tentar legitimar sua versão da história. Não só criar esse saber, mas reproduzir e reforçá-lo.

Esse filme, com uma base ideológica bastante explícita, define bem a frase "cinema é manipulação". Pois a narrativa fílmica se utiliza de vários elementos estéticos, como personagens, figurinos, ângulos e encenações, para representar um passado. Para Napolitano, (2008) o historiador deve perceber que:

Nos filmes históricos, essa questão é crucial, pois o importante não é apenas o que se encena do passado, mas como se encena e o que não se encena do processo ou evento histórico que inspirou o filme. Não se trata de cobrar do diretor a 
fidelidade ao evento encenado em todas as suas amplitudes e implicâncias, mas de perceber as escolhas e criticá-las dentro de uma estratégia de análise historiográfica (NAPOLITANO, 2008, p. 275).

Por fim, demonstra-se a possibilidade de averiguar, por alguns aportes teórico-metodológicos, o processo de apuração para que o filme possa servir como uma fonte. Uma gama de evidências para além da película, e permita assim dialogar com objeto de estudo e conseguir algumas respostas consistentes.

O historiador nada tem a perder utilizando fontes diversificadas na busca por respostas, a não ser coletando um maior número possível de informações que poderão mostrar resultados satisfatórios ou mesmo ampliar o leque de perguntas para novas perspectivas e averiguações de futuras pesquisas. Utiliza-se o cinema como mais um campo de investigação. Pois, como diria Ciro Flamarion Cardoso (1981), a História é uma ciência em construção.

\section{Considerações finais}

O presente artigo fez uma breve explanação do cinema como uma fonte histórica, ciente, que estudos continuam sendo elaborados para uma melhor definição. Além de uma abordagem mais abrangente que possa esclarecer dúvidas e problemas levantados na construção de um conhecimento ou fato histórico.

Foi demonstrado, através do filme alemão, $O$ Judeu Suss, produzido no calor da segunda guerra mundial, não só o produto fílmico em si, mas o seu contexto histórico, desde a criação do enredo, da narrativa, a busca pela representação da personagem judeu por relatos em arquivos da época. Para além, como o filme po- de dar pistas ao historiador como caminho de investigação sobre um determinado assunto, neste caso, a propaganda nazista por meio de películas cinematográficas.

Nesta análise fílmica, percebeu-se que a proposta da produção era de se fazer a película em uma ambientação histórica e de cunho biográfico, para poder dar mais veracidade a sua narrativa construída. Além de revelar algo do presente, na época do lançamento de $\mathrm{O}$ Judeu Suss, mesmo com uma história do passado, mas com uma representação do presente, dos judeus e de como sua história estaria carregada de atos criminosos que se perpetuariam na cultura alemã, caso eles não fossem parados. Esse discurso averiguado no filme serviu como forma de interpretar o cinema enquanto forma de expressão e de fonte para que possa compreender a realidade que o produz.

Assim, percebe-se a rede de sinais que o historiador conecta para buscar resolver seu problema. O filme, ao ser visto, estudado, analisado, endossa seu estatuto de fonte, ou como uma ferramenta auxiliar para buscar solucionar definições em aspectos intrafílmicos, no caso a análise fílmica, o extrafílmico, que seria a produção, distribuição e consequente recepção por parte dos telespectadores que podem levar ao cerne da questão.

Por fim, o filme Judeu Suss permite várias formas de interpretações. Cabe ao olhar atento do pesquisador elucidar as representações sociais existentes. Os modos de ver de um determinado assunto por meio desse dispositivo ótico, conhecido como cinema, mostra que numa sala escura, a percepção se foca para a tela e ali irá explorar um mundo desconhecido e complexo. Como diria Heitor Capuzzo, (1986) será a "aventura de um sonho". 


\section{Referências Bibliográficas}

AVELINO, Yvone dias. FLÓRIO, Marcelo. História cultural: o cinema como representação da vida cotidiana e suas interpretações. Projeto História, São Paulo, n. 48, Dez. 2013.

BARROS, José D’Assunção. A História Cultural e a contribuição de Roger Chartier. Diálogos - Revista do Departamento de História e do Programa de Pós-Graduação em História, vol. 9, núm. 1, UEM, Maringá. 2005, p. 125 $-141$.

BARROS, José D’Assunção. NÓVOA, Jorge. Cinema- história: teoria e representações sociais no cinema. 3. Ed. Rio de Janeiro: Apicuri. 2012.

BENJAMIN, Walter. A obra de arte na era de sua reprodutibilidade técnica. In: LIMA, Luiz Costa. Teoria da cul-

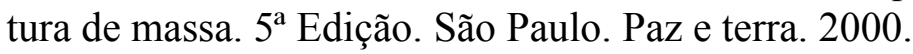

CAPUZZO, Heitor. Cinema: aventura do sonho. Coleção Portas abertas; V 12. São Paulo. Editora Nacional. 1986.

CARDOSO, Ciro Flamarion. Uma introdução a História. São Paulo: Ed. Brasiliense, 1981.

CARDOSO, Ciro Flamarion S. ROSA, Claudia Beltrão. Semiótica do espetáculo: um método para a História. Rio de janeiro: Apicuri, 2013.

CHARTIER, Roger. A História Cultural entre Práticas e Representações. Tradução de Maria Manuela Galhardo. DIFEL, 2002.

CHARTIER, Roger. A história ou a leitura do tempo. Tradução de Cristina Antunes. Belo Horizonte. Autêntica Editora, 2009.

CODATO, Henrique. Cinema e representações sociais: alguns diálogos possíveis. Verso e Reverso, vol. XXIV, n. 55, janeiro - abril, 2010. P. 47- 56

FERRO, MARC. O filme uma contra-análise da sociedade?In: LE Goff, J.; NORA, P. (Orgs). História: novos objetos. Trad.: Terezinha Marinho. Rio de Janeiro: F. Alves, 1976. p. 199- 215.

GOFF, Jacques Le. História e Memória. 5a ed. - Campinas, São Paulo: Editora da Unicamp, 2003.

GONZALES, Gerda Arns. Jud Süss - estetização da política antissemita na Alemanha nazista. Porto Alegre. 2014. TCC. UFRGS.

MORETTIN, Eduardo Victorio. O cinema como fonte histórica na obra de Marc Ferro. História: questões \& debates, Curitiba, n. 38, p. 11-42, Editora UFPR. 2003.

NAPOLITANO, Marcos. Fontes audiovisuais: A história depois do papel. In: PINSKY Carla Bassanezi. (Org.) Fontes históricas. 2 ed., $1^{\text {a }}$ reimpressão. - São Paulo: Contexto, 2008.

NÓVOA, Jorge. FRESSATO, Soleni Biscouto. FEIGELSON Kristian (organizadores) Cinematógrafo: um olhar sobre a história /. - Salvador: EDUFBA; São Paulo: Ed. da UNESP, 2009.

PESAVENTO, Sandra Jatahy. Em busca de uma Outra História: Imaginando o Imaginário. Revista Brasileira de História. São Paulo. V.15, n² 29. PP. 9-27, 1995.

ROSENFELD, Anatol. Cinema: arte e indústria. São Paulo. Editora Perspectiva S.A. 2002.

SCHVARZMAN, Sheilla. História e historiografia do cinema brasileiro: objetos do historiador. Cadernos de Ciências Humanas - Especiaria. V. 10, n. 17, jan./jun., 2007, p. 15-40.

SKLAR, Robert. História social do cinema americano. São Paulo: Editora Cultrix LTDA. 1975.

Submissão: 29/04/2017

Aceite: $24 / 01 / 2018$ 